\title{
Efficacy and safety of holmium laser enucleation of the prostate for elderly patients: surgical outcomes and King's Health Questionnaire
}

\author{
Go Anan^, Hiromichi Iwamura, Jotaro Mikami, Yuki Kohada, Jun Ito, Yasuhiro Kaiho, Makoto Sato \\ Department of Urology, Tohoku Medical and Pharmaceutical University, Sendai, Japan \\ Contributions: (I) Conception and design: G Anan, H Iwamura; (II) Administrative support: M Sato; (III) Provision of study materials or patients: G \\ Anan, H Iwamura, J Mikami, Y Kohada, J Ito, Y Kaiho; (IV) Collection and assembly of data: G Anan, H Iwamura, J Mikami; (V) Data analysis and \\ interpretation: G Anan; (VI) Manuscript writing: All authors; (VII) Final approval of manuscript: All authors. \\ Correspondence to: Go Anan, MD. Department of Urology, Tohoku Medical and Pharmaceutical University, 1-15-1 Fukumuro, Miyagino-ku, Sendai, \\ Miyagi, 983-8536, Japan. Email: goanan@tohoku-mpu.ac.jp.
}

Background: Holmium laser enucleation of the prostate (HoLEP) has been a widely utilized minimally invasive surgical procedure for benign prostate hyperplasia. The current study aimed to compare surgical outcomes and King's Health Questionnaire (KHQ) assessment scores following HoLEP between younger men and those aged $\geq 75$ years.

Methods: This prospective single-center study compared perioperative complications, postoperative urinary conditions, and KHQ scores (nine categories) between men aged $\geq 75$ years (group A) and men aged $<75$ years (group B) before and 1, 3, and 6 months after surgery.

Results: A total of 100 patients were included for analysis (group A, n=38 and group B, n=62). No differences in patient backgrounds, perioperative complications, such as perioperative decrease in hemoglobin, postoperative fever, postoperative indwelling catheterization duration, or postoperative hospitalization duration, and KHQ were observed between both groups. Both groups showed significantly better International Prostate Symptom Scores, quality of life, maximum urinary flow rate, and postvoid residual volume 1, 3, and 6 months after HoLEP compared to their respective preoperative levels $(\mathrm{P}<0.01)$. Regarding KHQ categories, both groups showed significantly better general health perceptions, impact on life, emotions, and sleep/energy 1 month after HoLEP; role limitations, physical limitations, and social limitations 3 months after HoLEP; and personal relationships and incontinence severity measures 6 months after HoLEP compared to their respective preoperative levels $(\mathrm{P}<0.05)$.

Conclusions: HoLEP could be safe and effective even for men aged $\geq 75$ years, comparing complications, urinary condition, and KHQ scores.

Keywords: Benign prostatic hyperplasia (BPH); Holmium laser enucleation of the prostate (HoLEP); King's Health Questionnaire (KHQ); quality of life (QoL); elderly

Submitted Oct 02, 2020. Accepted for publication Dec 13, 2020.

doi: $10.21037 /$ tau-20-1309

View this article at: http://dx.doi.org/10.21037/tau-20-1309

^ ORCID: 0000-0001-8325-2606. 


\section{Introduction}

Benign prostatic hyperplasia (BPH), a common condition among elderly males and affects over half of all men aged $>50$ years, develops in an age-related manner (1). Histologic evidence of $\mathrm{BPH}$ has been specifically identified in approximately $80-90 \%$ of men in their 70 s and 80 s (2). Lower urinary tract symptoms (LUTS) related to BPH have a negative impact on quality of life (QoL) (3). One study showed that older Japanese and American men have similar prevalence rates of LUTS due to BPH (4). Japan has experienced pronounced population aging and has currently the highest proportion of elderly adults worldwide (5), with approximately $27 \%$ of Japan's super-aging society being over 65 years.

Hiraoka et al. (6) first reported a series of enucleation of the prostate in 1986, and Gilling et al. (7) first performed a holmium laser enucleation of the prostate (HoLEP) for BPH in 1998. HoLEP has widely been used as a minimally invasive surgical procedure owing to the fact that it can be performed in patients with large-sized prostatic hyperplasia and is associated with relatively lower volumetric blood loss and shorter periods of indwelling catheterization and hospitalization than those of transurethral resection of the prostate (TURP) (8). Although postoperative transient urinary incontinence can be a bothersome complication within 3 months after HoLEP, only a few cases experience urinary incontinence for more than 6 months (9). There are some reports about the safety and efficacy of HoLEP in the elderly men $(10,11)$.

The King's Health Questionnaire (KHQ), which was originally developed to measure QoL among females with urge incontinence (12), is a validated tool used to measure health-related QoL in both males and females with LUTS (13-15), with one study demonstrating the validity of the Japanese version of the KHQ (16). To the best of our knowledge, no study has compared KHQ scores between elderly and younger men following HoLEP. The current study therefore aimed to compare HoLEP outcomes and KHQ scores between older (aged $\geq 75$ years) and younger males. We present the following article in accordance with the STROBE reporting checklist (available at http://dx.doi. org/10.21037/tau-20-1309).

\section{Methods}

The study was conducted in accordance with the Declaration of Helsinki (as revised in 2013) and study protocol (Protocol 2017-2-044) was approved by the ethical committee of Tohoku Medical and Pharmaceutical University Hospital School of Medicine, Sendai, Japan. Written informed consent was obtained from all patients prior to their participation. This study was registered with the University Hospital Medical Information Network Clinical Trials Registry in Japan (UMIN000041240).

\section{Study population}

This prospective single-center study included a total of 100 patients with BPH who underwent HoLEP at a single institution (Tohoku Medical and Pharmaceutical University Hospital) between May 2017 and March 2020. All consecutive patients were included in the analysis without any exclusion to avoid potential selection bias. Patients were subsequently divided into two groups: those aged $\geq 75$ years (Group A) and those aged $<75$ years (Group B). All patients underwent enucleation using the anteroposterior dissection three-lobe technique (17). We included men aged 50-90 years with symptoms of dysuria for the prior $\geq 3$ months of being enrolled in the study. Surgical indications included LUTS refractory to medical therapy, maximum urinary flow rate $(\mathrm{Qmax}) \leq 15 \mathrm{~mL} / \mathrm{s}$, International Prostate Symptom Score (IPSS) $\geq 8$, and prostate volume $\geq 30 \mathrm{~mL}$. Surgical indications excluded patients who could not tolerate general anesthesia, had severe dementia, or had performance status grades of 3 or 4 .

We preoperatively collected patient data for the following variables: age, body mass index (BMI), prostate volume (mL), IPSS, QoL score, Qmax, postvoid residual volume (PVR) (mL), International Consultation on Incontinence Questionnaire-Short Form (ICIQ-SF) score, and KHQ scores. We estimated preoperative prostate volume via magnetic resonance imaging. Furthermore, we evaluated and compared the intergroup values of total operative duration $(\mathrm{min})$, enucleation duration $(\mathrm{min})$, enucleate prostate weight $(\mathrm{g})$, enucleation efficacy rate $(\mathrm{g} / \mathrm{min})$, total energy $(\mathrm{kJ})$, and postoperative conditions, i.e., decreased perioperative hemoglobin $(\mathrm{g} / \mathrm{dL})$, hematuria, postoperative fever, postoperative indwelling catheterization duration, and postoperative hospitalization duration (days). We defined enucleation efficacy rate as the enucleated weight per minute $(\mathrm{g} / \mathrm{min})$; alternatively, we defined postoperative fever as a significant increase in body temperature of $>38.0{ }^{\circ} \mathrm{C}$. Additionally, we assessed the postoperative urinary condition and incontinence rates before and 1, 3, and 6 months after HoLEP. Patients were instructed to record 
the number of pads used per day. Incontinence was defined as the use of more than one pad per day, which included the use of safety pads.

The KHQ is an internationally validated specific QoL questionnaire that includes 21 items organized into the following 9 categories: general health perceptions, impact on life, role limitations, physical limitations, social limitations, personal relationships, emotions, sleep/energy, and incontinence severity measures. Scores for each category range from 0 to 100 , with a lower score indicating better QoL.

Prior to HoLEP, we performed urodynamic examination, which included free uroflowmetry, filling cystometry, and pressure flow studies. In addition, we also evaluated the maximum detrusor pressure, detrusor overactivity, volume at the first desire to void, maximum cystometric capacity, and residual volume.

\section{Surgical technique}

Enucleation was performed utilizing the anteroposterior dissection three-lobe technique, as previously reported (17). There are three enucleation techniques: one-lobe, two-lobe, and three-lobe. We chose the anteroposterior dissection HoLEP three-lobe technique because this method was reported to be a safe and effective enucleation method for inexperienced surgeons under appropriate guidance (17). All surgical procedures were performed or directly supervised by a single surgeon (G.A.) who has experience with more than 100 cases of HoLEP. HoLEP was performed using the following instruments: a 26-Fr continuous-flow resectoscope with a laser bridge adapter (Olympus, Tokyo, Japan), Versa Pulse Select $100 \mathrm{~W}^{\circledR}$ laser beam generator (Lumenis, Yokneam, Israel), and laser fiber Slim Line $550 \mu \mathrm{m}$ (Lumenis) used for adenoma enucleation. The laser output was set to $78 \mathrm{~W}$ $(2.6 \mathrm{~J} \times 30 \mathrm{~Hz})$ for enucleation and $25 \mathrm{~W}(0.5 \mathrm{~J} \times 50 \mathrm{~Hz})$ for hemostasis. Enucleate prostate morcellation was performed using a 26-Fr rigid nephroscope (Olympus) and morcellation device VersaCut System ${ }^{\circledR}$ (Lumenis). Physiological saline was used as the perfusion solution. Notably, the final hemostasis after morcellation was always performed using a transurethral resection in saline system (TURis System ${ }^{\circledR}$, Olympus) with a 26-Fr rigid nephroscope (Olympus). We removed the urinary catheter on the second day after HoLEP, following which we confirmed the self-urination and degree of urinary incontinence.

\section{Statistical analysis}

Patient characteristics are presented as means and standard deviations or ranges for continuous variables. We assessed the intergroup differences in continuous variables using the Mann-Whitney $U$ test and Wilcoxon signed-rank test and categorical variables using the Fisher's exact test for. All statistical analyses were performed using JMP version 9.0 (SAS Institute Inc., Cary, NC, USA) with P values $<0.05$ indicating statistical significance.

\section{Results}

A total of 100 patients were include for analysis (group $\mathrm{A}, \mathrm{n}=38$ and group $\mathrm{B}, \mathrm{n}=62$ ). Accordingly, no differences in patient backgrounds, including BMI, IPSS, QoL score, Overactive Bladder Symptom Score (OABSS), ICIQ-SF score, prostate volume, Qmax, PVR, voiding volume, preoperative urinary retention, and preoperative comorbidities (such as hypertension, diabetes, hyperlipidemia, excluding age and preoperative cardiovascular disease) was observed between both groups (Table 1). Regarding the urodynamic examination results, group A had significantly lower maximum detrusor pressure $\left(83\right.$ vs. $97 \mathrm{cmH}_{2} \mathrm{O}$; $\mathrm{P}=0.02)$, volume at the first desire to void $(234$ vs. $282 \mathrm{~mL}$; $\mathrm{P}=0.04)$, and maximum cystometric capacity (305 vs. $406 \mathrm{~mL}$; $\mathrm{P}=0.01)$. There were no differences between groups $\mathrm{A}$ and $\mathrm{B}$ in terms of detrusor overactivity ( $18 \%$ vs. $15 \%$; $\mathrm{P}=0.78)$.

As shown in Table 2, no significant intergroup differences in total operative duration (97 vs. $90 \mathrm{~min}$ ), enucleation duration (45 vs. $46 \mathrm{~min}$ ), enucleate prostate weight (47 vs. $39 \mathrm{~g}$ ), enucleation efficacy ( 1.02 vs. $0.86 \mathrm{~g} / \mathrm{min})$, total energy (149 vs. $145 \mathrm{KJ}$ ), perioperative hemoglobin decrease ( 1.2 vs. $1.4 \mathrm{~g} / \mathrm{dL})$, postoperative fever $(3 \%$ vs. $2 \%)$, cases requiring postoperative transurethral coagulation $(0 \%$ $v s .0 \%)$, postoperative transient urinary retention $(0 \% v s$. $3 \%)$, postoperative indwelling catheterization duration (2 $v s .2$ days), or postoperative hospitalization duration (4 vs. 4 days). All patients successfully underwent anteroposterior dissection three-lobe technique, with no cases requiring switching to TURP. No patient required transurethral resection and coagulation or blood transfusion due to postoperative hematuria or blood loss, respectively. There were no significant intergroup differences with regard to any of the complications.

As shown in Table 3, group A had significantly lower Qmax (12.3 vs. $15.8 \mathrm{~mL} / \mathrm{s}, \mathrm{P}=0.03,1$ month; 13.2 vs. $17.9 \mathrm{~mL} / \mathrm{s}$, 
Table 1 Comparison of the patient characteristics

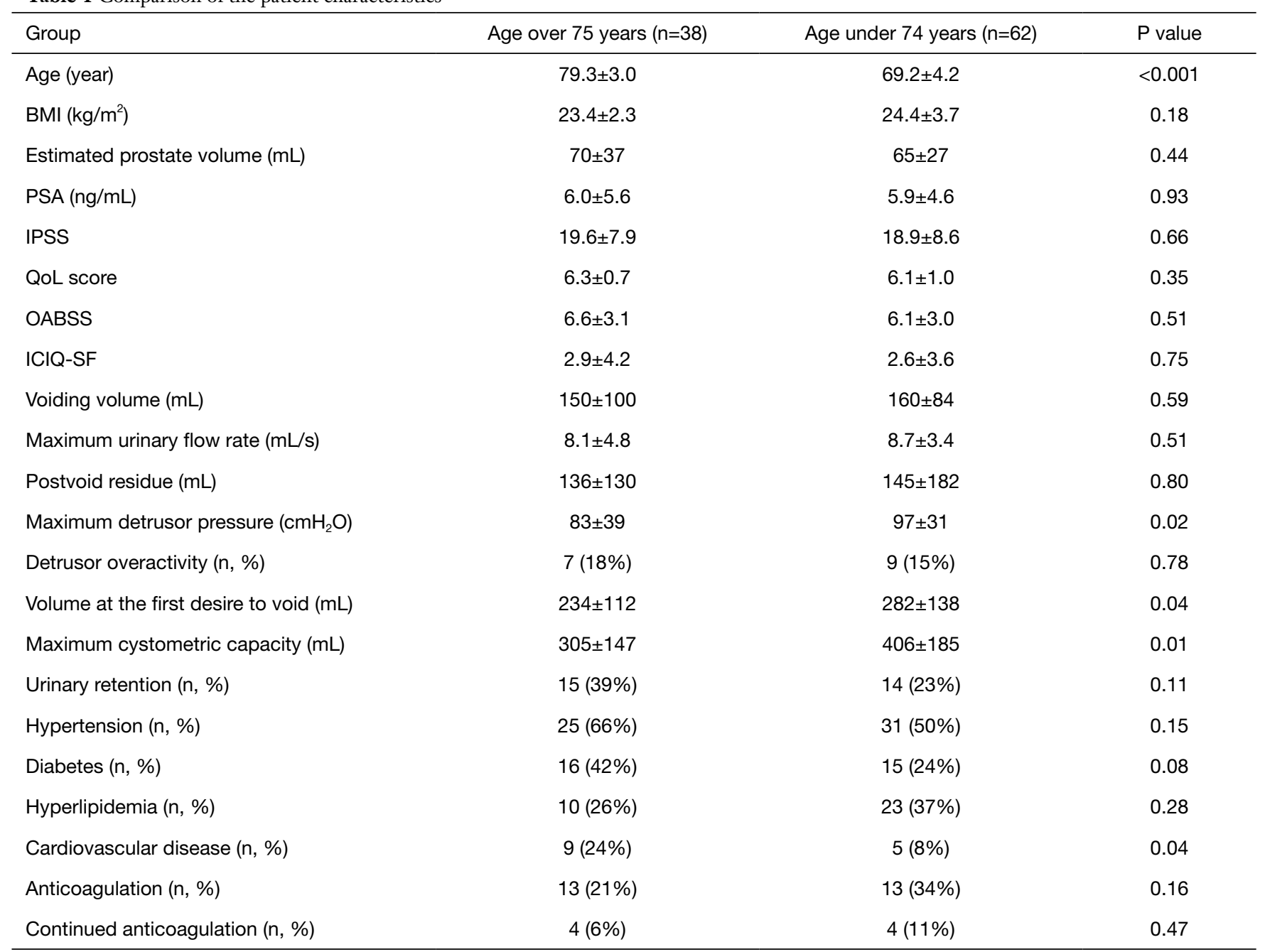

Data are shown as sample mean and standard deviation or counts (percent of total). BMI, body mass index; IPSS, International Prostate Symptom Score; QoL, quality of life; Qmax, maximum flow rate; PVR, postvoid residual volume; OABSS, Overactive Bladder Symptom Score; ICIQ-SF, International Consultation on Incontinence Questionnaire-Short Form.

$\mathrm{P}=0.03,3$ months $)$ and voiding volume (138 vs. $176 \mathrm{~mL}$, $\mathrm{P}=0.047,1$ month; 138 vs. $199 \mathrm{~mL}, \mathrm{P}=0.003,3$ months) than group B 1 and 3 months after HoLEP. However, no significant intergroup differences in Qmax (17.0 vs. $19.3 \mathrm{~mL} / \mathrm{s})$ and voiding volume $(179 \mathrm{vs.} 222 \mathrm{~mL})$ were noted 6 months after HoLEP. Moreover, no significant intergroup differences in IPSS, QoL score, OABSS, ICIQ-SF score, PVR, or urinary incontinence rate were observed 1,3 , and 6 months after HoLEP. Both groups showed significantly better IPSS, QoL, Qmax, and PVR 1, 3, and 6 months after HoLEP compared to their respective preoperative levels $(\mathrm{P}<0.01)$ (Figure 1).

As shown in Table 4, no significant intergroup differences in all 9 categories, including general health perceptions, impact on life, role limitations, physical limitations, social limitations, personal relationships, emotions, sleep/energy, and incontinence severity measures, were observed before and 1, 3, and 6 months after surgery. Both groups showed significantly lower scores for general health perceptions, impact on life, emotions, and sleep/energy at 1, 3, and 6 months after HoLEP compared to their respective preoperative scores $(\mathrm{P}<0.05)$. Moreover, both groups showed significantly lower scores for role limitations, physical limitations, and social limitations 3 and 6 months after HoLEP compared to their respective preoperative scores $(\mathrm{P}<0.05)$. Finally, both groups showed significantly 
Table 2 Comparison of the surgical outcomes and postoperative complications

\begin{tabular}{lccc}
\hline Group & Age over 75 years $(\mathrm{n}=38)$ & Age under 74 years $(\mathrm{n}=62)$ & $\mathrm{P}$ value \\
\hline Total operation duration (min) & $97 \pm 31$ & $90 \pm 30$ & 0.25 \\
Enucleation duration (min) & $46 \pm 14$ & $45 \pm 15$ & 0.64 \\
Enucleate prostate weight (g) & $47 \pm 34$ & $39 \pm 24$ & 0.15 \\
Enucleation efficacy (g/min) & $1.02 \pm 0.56$ & $0.86 \pm 0.41$ & $145 \pm 45$ \\
Total energy (KJ) & $149 \pm 43$ & $1.4 \pm 0.7$ & 0.10 \\
Hemoglobin decreases (g/dL) & $1.2 \pm 0.9$ & $1(2 \%)$ & 0.11 \\
Postoperative fever (n, \%) & $1(3 \%)$ & $2(3 \%)$ & 1.00 \\
Transient urinary retention (n, \%) & $0(0 \%)$ & $2.0 \pm 0.2$ & 0.52 \\
Catheter-indwelling period (days) & $2.0 \pm 0.0$ & $4 \pm 0.5$ & 0.27 \\
Postoperative hospital period (days) & $4 \pm 0.3$ & 0.11 \\
\hline
\end{tabular}

Data are shown as sample mean and standard deviation or counts (percent of total).

Table 3 Comparison of urinary conditions 1, 3, and 6 months postoperatively

\begin{tabular}{|c|c|c|c|}
\hline Group & Age over 75 years $(n=38)$ & Age under 74 years $(n=62)$ & $P$ value \\
\hline \multicolumn{4}{|c|}{ Voiding volume $(\mathrm{mL})$} \\
\hline 1 month & $138 \pm 81$ & $176 \pm 98$ & 0.047 \\
\hline 3 months & $138 \pm 80$ & $199 \pm 99$ & 0.003 \\
\hline 6 months & $179 \pm 110$ & $222 \pm 103$ & 0.08 \\
\hline 1 month & $12.3 \pm 5.0$ & $15.8 \pm 9.0$ & 0.03 \\
\hline 3 months & $13.2 \pm 5.9$ & $17.9 \pm 11.1$ & 0.03 \\
\hline 6 months & $17.0 \pm 9.2$ & $19.3 \pm 9.8$ & 0.31 \\
\hline \multicolumn{4}{|c|}{ Postvoid residue (mL) } \\
\hline 6 months & $14 \pm 10$ & $13 \pm 11$ & 0.66 \\
\hline \multicolumn{4}{|l|}{ IPSS } \\
\hline 1 month & $9.4 \pm 6.9$ & $8.2 \pm 6.8$ & 0.40 \\
\hline 3 months & $6.5 \pm 3.9$ & $5.8 \pm 4.3$ & 0.43 \\
\hline 6 months & $5.1 \pm 3.3$ & $3.9 \pm 2.6$ & 0.08 \\
\hline \multicolumn{4}{|l|}{ QoL score } \\
\hline 1 month & $3.2 \pm 1.6$ & $3.2 \pm 1.7$ & 0.93 \\
\hline 3 months & $2.6 \pm 1.2$ & $2.6 \pm 1.4$ & 0.82 \\
\hline
\end{tabular}

Table 3 (continued) 
Table 3 (continued)

\begin{tabular}{lccc}
\hline Group & Age over 75 years $(\mathrm{n}=38)$ & Age under 74 years $(\mathrm{n}=62)$ & $\mathrm{P}$ value \\
\hline 1 month & $6.5 \pm 3.0$ & $6.0 \pm 3.6$ & 0.48 \\
3 months & $4.9 \pm 2.3$ & $4.4 \pm 3.1$ & 0.41 \\
6 months & $1.7 \pm 2.5$ & $1.4 \pm 2.1$ & 0.66 \\
ICIQ-SF score & & & 0.90 \\
1 month & $5.5 \pm 4.6$ & $6.0 \pm 3.6$ & 0.19 \\
3 months & $4.3 \pm 4.0$ & $3.1 \pm 3.9$ & 0.66 \\
6 months & $1.7 \pm 2.5$ & $1.4 \pm 2.1$ & 1.00 \\
Urinary incontinence rate $(\%)$ & & & 0.40 \\
1 month & $18(47 \%)$ & $30(48 \%)$ & 0.56 \\
3 months & $8(21 \%)$ & $8(13 \%)$ & $1(2 \%)$ \\
6 months & $2(5 \%)$ & & \\
\hline
\end{tabular}

Data are shown as sample mean and standard deviation. IPSS, International Prostate Symptom Score; QoL, quality of life; Qmax, maximum flow rate; PVR, postvoid residual volume; OABSS, Overactive Bladder Symptom Score; ICIQ-SF, International Consultation on Incontinence Questionnaire-Short Form.
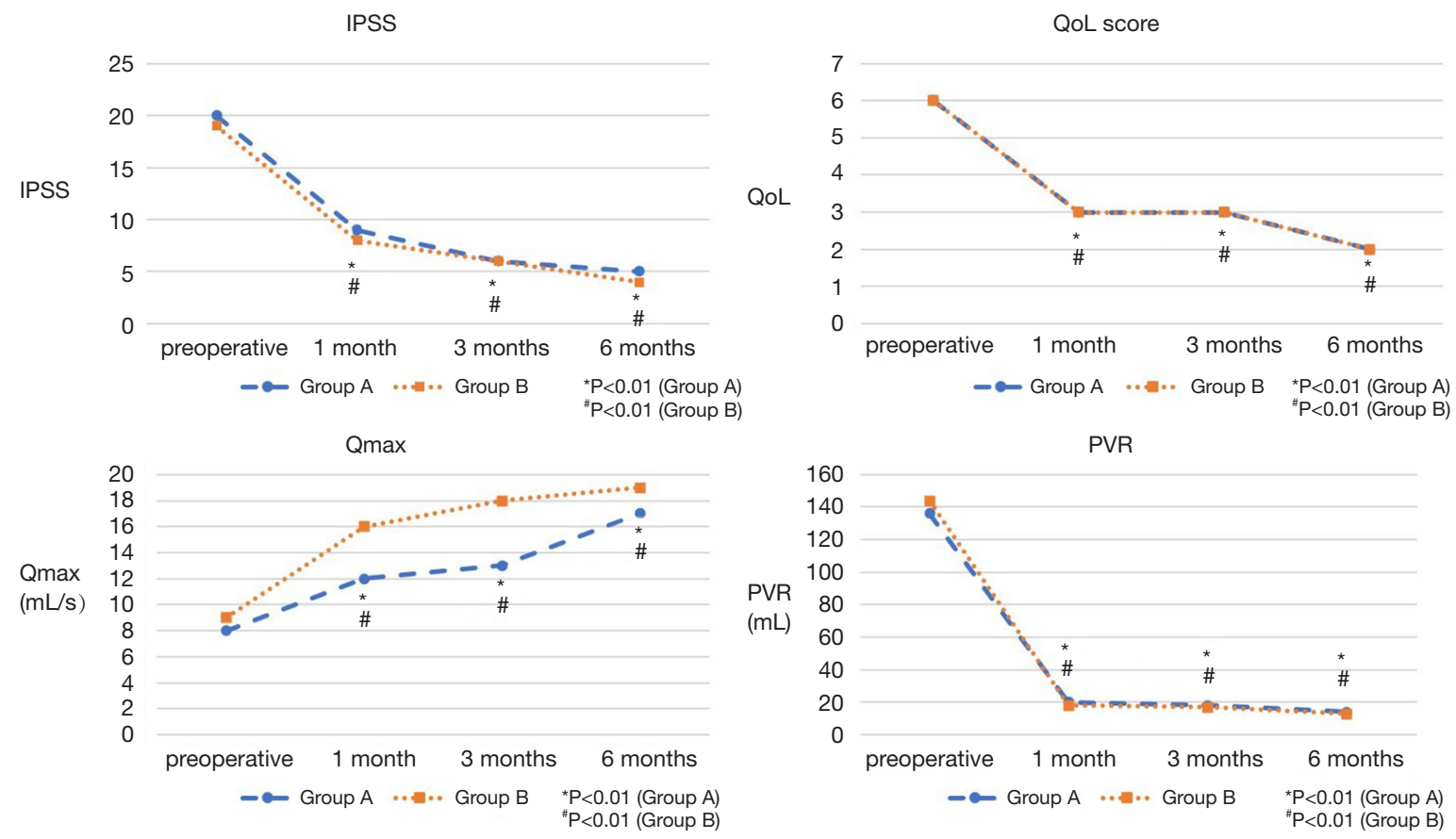

Figure 1 Comparison of IPSS, QoL score, Qmax, and PVR in groups A and B. P value, comparison between the preoperative parameters and postoperative parameters using Wilcoxon signed-rank test. IPSS, International Prostate Symptom Score; QoL, quality of life; Qmax, maximum flow rate; PVR, postvoid residual volume; HoLEP, holmium laser enucleation of the prostate. 
Table 4 Comparison of King's Health Questionnaire scores preoperatively and 1, 3, and 6 months postoperatively

\begin{tabular}{|c|c|c|c|}
\hline Group & Age over 75 years $(n=38)$ & Age under 74 years $(n=62)$ & $P$ value \\
\hline Pre & $40 \pm 18$ & $35 \pm 22$ & 0.35 \\
\hline 1 month & $30 \pm 20$ & $26 \pm 18$ & 0.24 \\
\hline 3 months & $30 \pm 18$ & $26 \pm 18$ & 0.31 \\
\hline \multicolumn{4}{|c|}{ Impact on life } \\
\hline Pre & $43 \pm 28$ & $44 \pm 28$ & 0.92 \\
\hline 1 month & $28 \pm 25$ & $30 \pm 27$ & 0.78 \\
\hline 3 months & $21 \pm 21$ & $20 \pm 22$ & 0.89 \\
\hline Pre & $26 \pm 31$ & $26 \pm 26$ & 0.95 \\
\hline 1 month & $22 \pm 27$ & $21 \pm 25$ & 0.82 \\
\hline 3 months & $11 \pm 17$ & $12 \pm 17$ & 0.75 \\
\hline 6 months & $6 \pm 11$ & $5 \pm 10$ & 0.64 \\
\hline \multicolumn{4}{|c|}{ Physical limitations } \\
\hline Pre & $30 \pm 30$ & $28 \pm 27$ & 0.86 \\
\hline 1 month & $25 \pm 21$ & $23 \pm 27$ & 0.71 \\
\hline 3 months & $16 \pm 16$ & $15 \pm 20$ & 0.74 \\
\hline 6 months & $1 \pm 5$ & $3 \pm 9$ & 0.25 \\
\hline \multicolumn{4}{|c|}{ Personal relationships } \\
\hline Pre & $9 \pm 21$ & $6 \pm 18$ & 0.47 \\
\hline 1 month & $4 \pm 14$ & $8 \pm 18$ & 0.22 \\
\hline 3 months & $2 \pm 9$ & $4 \pm 16$ & 0.49 \\
\hline 6 months & $0 \pm 9$ & $2 \pm 11$ & 0.08 \\
\hline \multicolumn{4}{|l|}{ Emotions } \\
\hline Pre & $32 \pm 30$ & $32 \pm 30$ & 0.92 \\
\hline 1 month & $20 \pm 24$ & $20 \pm 26$ & 0.93 \\
\hline 3 months & $9 \pm 14$ & $12 \pm 20$ & 0.43 \\
\hline 6 months & $5 \pm 10$ & $6 \pm 13$ & 0.71 \\
\hline
\end{tabular}

Table 4 (continued) 
Table 4 (continued)

\begin{tabular}{lccc}
\hline Group & Age over 75 years $(n=38)$ & Age under 74 years $(n=62)$ & P value \\
\hline Sleep/energy & & & 0.23 \\
Pre & $35 \pm 28$ & $28 \pm 28$ & 0.74 \\
1 month & $18 \pm 21$ & $19 \pm 24$ & 0.66 \\
3 months & $9 \pm 14$ & $11 \pm 19$ & 0.96 \\
6 months & $7 \pm 13$ & $7 \pm 13$ & 0.19 \\
Incontinence (severity measures) & & & 0.76 \\
Pre & $22 \pm 24$ & $17 \pm 19$ & 0.69 \\
1 month & $25 \pm 19$ & $26 \pm 23$ & 0.58 \\
3 months & $16 \pm 13$ & $15 \pm 17$ & $6 \pm 9$ \\
6 months & $5 \pm 7$ & & \\
\hline
\end{tabular}

Data are shown as sample mean and standard deviation.

lower scores for personal relationships and incontinence severity measures 6 months after HoLEP compared to their respective preoperative scores $(\mathrm{P}<0.05)$. Among the nine KHQ categories, personal relationships and incontinence severity measures took longer to improve postoperatively.

\section{Discussion}

This study showed no significant differences in the catheterization duration, postoperative hospitalization duration, postoperative complications (such as postoperative fever, hematuria clot retention, or transient urinary retention), and KHQ-QoL scores comparing patients $\geq 75$ years with patients $<75$ years. These results suggest that HoLEP is safe and useful for elderly patients. One of the benefits of HoLEP is its association with low incidences of perioperative and late complications $(18,19)$. Studies report that HoLEP is a relatively safe and effective surgical treatment for BPH, regardless of age (10). However, elderly individuals aged $\geq 80$ years were reported to require significantly longer hospitalizations following HoLEP than that by younger age groups (11). To the best of our knowledge, this is the first HoLEP series to utilize KHQ to compare QoL between the elderly and younger patients. Our findings revealed that both groups exhibited significant improvements in all nine KHQ categories, namely the general health perceptions, impact on life, emotions, and sleep/energy after 1 month, role limitations, physical limitations, and social limitations after 3 months, personal relationships and incontinence severity measures after 6 months. At all durations, no significant differences in all KHQ categories were observed. Therefore, the present study suggests that elderly patients had a similar QoL to those of younger patients following HoLEP.

Elderly men with dysuria often show slower improvements after treatment, whether surgical or pharmacological therapy, than younger men under similar conditions (20). The present study found that patients $\geq 75$ years had significantly lower improvements in voiding volume and Qmax than that in patients $<75$ years 1 and 3 months after HoLEP. However, such differences disappeared at 6 months after HoLEP. This may have been due to several factors, one of which is bladder dysfunction. Generally, elderly men can be considered to have suffered from the disease longer, which might require a longer period to improve. The present study showed that patients $\geq 75$ years had significantly lower preoperative maximum detrusor pressure, volume at the first desire to void, and maximum cystometric capacity than that in those $<75$ years. Among patients $\geq 75$ years, the preoperative decrease in detrusor pressure and bladder capacity might suggest a gradual postoperative improvement in voiding volume and Qmax, a finding comparable to those in previous reports $(21,22)$.

Perioperative complications and mortality need to be considered in elderly patients. Surgical morbidity typically showed a linear increase across all age groups. Patients with $\mathrm{BPH}$ aged $>70$ years and presenting with significant comorbidities are considered high-risk patients (23). Accordingly, Uchida et al. found that age was an independent 
predictor for post-TURP morbidity and blood transfusions in a large cohort study of 3861 patients (24). Moreover, Matani et al. reported that $25.9 \%$ and $13.2 \%$ of patients who underwent TURP presented with early and late complications, respectively (25). However, a recent study with 311 patients who underwent HoLEP procedures reported that overall morbidity, hospital stay, and 1-year functional outcomes were similar among the 50-59, $60-69,70-79$, and $\geq 80$ years age groups (10). Another study found that patients $\geq 80$ years had significant longer hospital stay than those $<80$ years due to the need for longer catheterizations in the former (11). The present study found no significant differences in perioperative complications, including decreased hemoglobin, postoperative transurethral coagulation, postoperative fever, and postoperative transient urinary retention, as well as postoperative indwelling catheterization duration and postoperative hospitalization duration, between patients $\geq 75$ and $<75$ years.

The current study has several limitations. First, this study included a limited number of patients recruited from a single-center. Second, the follow-up period was relatively short. As such, future studies need include more patients observed over a longer follow-up period in order to better determine efficacy of HoLEP. Third, the elderly group of patients who underwent HoLEP in this study were more likely to be in relatively good general condition and capable of general anesthesia. However, after comparing surgical outcomes and KHQ between patients $\geq 75$ and $<75$ years, we found that patients older than 75 years can undergo HoLEP for BPH with acceptable complication rates and postoperative QoL.

\section{Conclusions}

The current study found that HoLEP can be safe and effective even among elderly men aged $\geq 75$ years, with surgical outcomes and KHQ scores comparable to those of younger men.

\section{Acknowledgments}

Funding: None.

\section{Footnote}

Reporting Checklist: The authors have completed the STROBE reporting checklist. Available at http://dx.doi. org/10.21037/tau-20-1309
Data Sharing Statement: available at http://dx.doi. org/10.21037/tau-20-1309

Conflicts of Interest: All authors have completed the ICMJE uniform disclosure form (available at http://dx.doi. org/10.21037/tau-20-1309). The authors have no conflicts of interest to declare.

Ethical Statement: The authors are accountable for all aspects of the work in ensuring that questions related to the accuracy or integrity of any part of the work are appropriately investigated and resolved. The study was conducted in accordance with the Declaration of Helsinki (as revised in 2013). The study was approved by institutional committee of Tohoku Medical and Pharmaceutical University Hospital School of Medicine (2017-2-044) and informed consent was obtained from all patients.

Open Access Statement: This is an Open Access article distributed in accordance with the Creative Commons Attribution-NonCommercial-NoDerivs 4.0 International License (CC BY-NC-ND 4.0), which permits the noncommercial replication and distribution of the article with the strict proviso that no changes or edits are made and the original work is properly cited (including links to both the formal publication through the relevant DOI and the license). See: https://creativecommons.org/licenses/by-nc-nd/4.0/.

\section{References}

1. Lokeshwar SD, Harper BT, Webb E, et al. Epidemiology and treatment modalities for the management of benign prostatic hyperplasia. Transl Androl Urol 2019;8:529-39.

2. Bushman W. Etiology, epidemiology, and natural history of benign prostatic hyperplasia. Urol Clin North Am 2009;36:403-15.

3. Giuliano F. Lower urinary tract symptoms and sexual dysfunction: a common approach. BJU Int 2008;101:22-6.

4. Tsukamoto T, Kumamoto Y, Masumori N, et al. Prevalence of prostatism in Japanese men in a communitybased study with comparison to a similar American study. J Urol 1995;154:391-5.

5. Chen BK, Jalal H, Hashimoto $\mathrm{H}$, et al. Forecasting trends in disability in a super-aging society: adapting the future elderly model to Japan. J Econ Ageing 2016;8:42-51.

6. Hiraoka Y, Lin T, Tsuboi N, et al. Transurethral enucleation of benign prostatic hyperplasia. Nihon Ika 
Daigaku Zasshi 1986;53:212-5.

7. Gilling PJ, Kennett K, Das AK, et al. Holmium laser enucleation of the prostate (HoLEP) combined with transurethral tissue morcellation: an update on the early clinical experience. J Endourol 1998;12:457-9.

8. Cornu JN, Ahyai S, Bachmann A, et al. A systematic review and meta-analysis of functional outcomes and complications following transurethral procedures for lower urinary tract symptoms resulting from benign prostatic obstruction: an update. Eur Urol 2015;67:1066-96.

9. Anan G, Kaiho Y, Iwamura H, et al. Preoperative pelvic floor muscle exercise for early continence after holmium laser enucleation of the prostate: a randomized controlled study. BMC Urol 2020;20:3.

10. Mmeje CO, Nunez-Nateras R, Warner JN, et al. Agestratified outcomes of holmium laser enucleation of the prostate. BJU Int 2013;112:982-9.

11. Piao S, Choo MS, Kim M, et al. Holmium laser enucleation of the prostate is safe for patients above 80 years: a prospective study. Int Neurourol J 2016;20:143-50.

12. Kelleher CJ, Cardozo LD, Khullar V, et al. A new questionnaire to assess the quality of life of urinary incontinent women. Br J Obstet Gynaecol 1997;104:1374-9.

13. Watson V, Ryan M, Brown CT, et al. Eliciting preferences for drug treatment of lower urinary tract symptoms associated with benign prostatic hyperplasia. J Urol 2004;172:2321-5.

14. Reese PR, Pleil AM, Okano GJ, et al. Multinational study of reliability and validity of the King's Health Questionnaire in patients with overactive bladder. Qual Life Res 2003;12:427-42.

15. Okamura K, Usami T, Nagahama K, et al. "Quality of life" assessment of urination in elderly Japanese men and women with some medical problems using International Prostate Symptom Score and King's Health Questionnaire.
Eur Urol 2002;41:411-9.

16. Homma Y, Ando T, Yoshida M, et al. Validation of the Japanese version of QOL questionnaires for urinary incontinence. NBS 2002;13:247-57.

17. Anan G, Kaiho Y, Iwamura H, et al. Anteroposterior dissection three-lobe technique: an effective surgical method for inexperienced surgeons performing holmium laser enucleation of the prostate. Int Urol Nephrol 2020;52:1821-8.

18. Elzayat EA, Habib EI, Elhilali MM. Holmium laser enucleation of the prostate: a size-independent new 'gold standard'. Urology 2005;66:108-13.

19. Vavassori I, Valenti S, Naspro R, et al. Three-year outcome following holmium laser enucleation of the prostate combined with mechanical morcellation in 330 consecutive patients. Eur Urol 2008;53:599-604.

20. Chen X, Man Q, Wei X, et al. Predictive value of preoperative comprehensive evaluation on the efficacy of HoLEP. Transl Androl Urol 2020;9:1603-10.

21. Smith PP. Aging and the underactive detrusor: a failure of activity or activation? Neurourol Urodyn 2010;29:408.

22. Namitome R, Takei M, Takahashi R, et al. A prediction model of detrusor underactivity based on symptoms and noninvasive test parameters in men with lower urinary tract symptoms: an analysis of a large group of patients undergoing pressure-flow studies. J Urol 2020;203:779-85.

23. Lusuardi L, Hruby S, Janetschek G. New emerging technologies in benign prostatic hyperplasia. Curr Opin Urol 2013;23:25-9.

24. Uchida T, Ohori M, Soh S, et al. Factors influencing morbidity in patients undergoing transurethral resection of the prostate. Urology 1999;53:98-105.

25. Matani Y, Mottrie AM, Stockle M, et al. Transurethral prostatectomy: a long-term follow-up study of 166 patients over 80 years of age. Eur Urol 1996;30:414-7.
Cite this article as: Anan G, Iwamura H, Mikami J, Kohada Y, Ito J, Kaiho Y, Sato M. Efficacy and safety of holmium laser enucleation of the prostate for elderly patients: surgical outcomes and King's Health Questionnaire. Transl Androl Urol 2021;10(2):775-784. doi: 10.21037/tau-20-1309 